\title{
Palladium-Catalyzed Asymmetric Allylic Alkylation of meso- and dl-1,2-Divinylethylene Carbonate
}

\author{
Barry M. Trost and Aaron Aponick \\ Department of Chemistry, Stanford University, Stanford, California 94305-5080
}

The development of new reactions that produce enantiomerically pure compounds from inexpensive readily available achiral or racemic starting materials represents a continuing major challenge. In our efforts directed towards this goal, we have explored palladiumcatalyzed asymmetric allylic alkylation (Pd AAA) processes that rely on either the ionization of enantiotopic leaving groups or nucleophilic addition to chiral $\pi$-allylpalladium complexes as the enantiodetermining steps. ${ }^{1,2}$ Herein we wish to report the first example whereby both methods of enantiodiscrimination act in concert to produce chiral materials in high ee.

Based on the successful palladium-catalyzed dynamic kinetic asymmetric transformation (DYKAT) of racemic butadiene monoepoxide, ${ }^{3}$ we postulated that a triene monoepoxide, or surrogate thereof, may behave similarly and generate two new stereogenic centers in high optical purity. The reaction products using heteroatom nucleophiles would hopefully be monoprotected diols and $N$-protected amino alcohols with both heteroatoms and all six carbon atoms differentiated in the reaction. Use of these diols in efficient synthetic schemes has recently been reported, ${ }^{4}$ but the starting materials are prepared from the chiral pool and require multi-step procedures. A catalytic enantioselective preparation of these synthons would provide direct access to either enantiomer in a single operation.

The parent triene monoepoxide required, hexatriene monoepoxide, was predicted to be more difficult to prepare and handle than desired so 1,2-divinylethylene carbonate ${ }^{5}(\mathbf{2}$ and $\mathbf{3}$ ) was chosen as a surrogate. Reductive dimerization 6 of $\mathbf{1}$ followed by cyclization provided the $d l$ and meso- isomers $\mathbf{2}$ and $\mathbf{3}$ as a 1:1 mixture of separable diastereomers in good yield.

The products of the Pd AAA of $\mathbf{2}$ and $\mathbf{3}$ by the well-established double inversion mechanism ${ }^{7}$ were expected to be diastereomers 4 and 5 respectively, neglecting the regiochemistry of the nucleophilic addition (Scheme 1). With the goal of finding both a nitrogen and an oxygen nucleophile that would serve as easily deprotected functional groups in the product, preliminary studies focused on employing phthalimide $\mathbf{6}$ in the desired reaction (Table 1). When the $d l$-carbonate 2 was allowed to react with phthalimide in the presence of $5 \mathrm{~mol}$ $\% \pi$-allylpalladium chloride dimer 7, $15 \mathrm{~mol} \%$ racemic 8 , and $5 \mathrm{~mol} \% \mathrm{Na}_{2} \mathrm{CO}_{3}$ in $\mathrm{CH}_{2} \mathrm{Cl}_{2}, 3$ the only product isolated was the expected amino alcohol $9^{8}$ in $81 \%$ yield (entry 1 , Table 1 ). Using ligand (R,R)-8 with $5 \mathrm{~mol} \%$ and $2 \mathrm{~mol} \% \mathbf{7}$ (entries 2,3), 9 was again isolated as the sole product in $>99 \%$ ee but with $44 \%$ and $43 \%$ yield respectively, due to kinetic resolution of racemic 2 (vide infra).

The reaction was next attempted with the cyclic carbonate $\mathbf{3}$ (entries 4-6) to determine how well the catalyst system would work with a dienyl meso compound, a class of substrates that has not been explored in intermolecular Pd AAA reactions. ${ }^{9}$ To our surprise, using both racemic $\mathbf{8}$ and $(\boldsymbol{R}, \boldsymbol{R})-\mathbf{8}$ the only product formed was the unexpected syn diastereomer $\mathbf{9}$ (entries 
4 and 5). In both reactions the yield was acceptable and in entry 5 the ee was $>99 \%$. The catalyst loading could also be reduced ( 2 mol\% 7, entry 6) while maintaining both yield and ee. Since $\mathbf{2}$ and $\mathbf{3}$ are prepared in the same reaction and both exclusively gave product $\mathbf{9}$ with excellent ee, the reaction was carried out on a 1:1 mixture of $\mathbf{2}$ and $\mathbf{3}$ obtained from $\mathbf{1}$. Under optimized conditions with prolonged reaction time, the process performed equally well giving $\mathbf{9}$ with $>99 \%$ ee using 1 mol\% 7 in $74 \%$ yield (based on charged $\mathbf{2}+\mathbf{3}$ ) wherein the maximum theoretical yield is $75 \%$ based upon the dual enantiodiscrimination mechanisms. Interestingly, the cyclic carbonate $(R, R)-2$, recovered in $16 \%$ yield (theoretical max. $25 \%$ ), has a $91 \%$ ee, indicative of a kinetic resolution of racemic 2 by the chiral catalyst system.

The mechanistic scenario for this process to occur was intriguing based on our prior observations. Previously, two discrete situations with different mechanistic circumstances have been observed whereby the enantiodetermining steps of the reactions are postulated to be separate steps of the catalytic cycle. When nucleophilic addition to the initially formed $\pi$-allyl occurs faster than equilibration, the ionization step of the catalytic cycle is the stage at which the enantioselctivity is determined, and overall retention of stereochemistry is observed. If interconversion of the diastereomeric $\pi$-allylpalladium complexes is faster than nucleophilic addition, the addition step is enantiodetermining, and products that have overall inversion of stereochemistry may arise by an outer sphere process. Under ideal conditions, coupling these two pathways may provide a suitable manifold for the conversion of racemic diastereomeric starting materials into a single compound in high ee. If reactions of $\mathbf{2}$ and $\mathbf{3}$ are treated separately (Table 1, entries 1-3 vs. 4-6), both types of enantiodiscrimination are postulated to be occurring.

Using the wall and flap diagram to represent the chiral ligand scaffold, ${ }^{10}$ the proposed mechanism of this transformation is illustrated in Scheme 2. In matched processes, both ionization of the leaving group and nucleophilic addition occur from under the flap of the ligand to avoid contact with the wall. When considering how these cyclic carbonates interact with the catalyst, treatment of the kinetic resolution of racemic $\mathbf{2}$ is straightforward. Employing ligand $(\boldsymbol{R}, \boldsymbol{R})-\mathbf{8},(\boldsymbol{S}, \boldsymbol{S})-\mathbf{9}$ is produced from $(\boldsymbol{S}, \boldsymbol{S})-2$ leaving unreacted $(\boldsymbol{R}, \boldsymbol{R})-2$ in high optical purity. This is consistent with the model, in that ionization of $(\boldsymbol{S}, \boldsymbol{S})-\mathbf{2}$ is predicted to be a matched pair using $(\boldsymbol{R}, \boldsymbol{R})-\mathbf{8}$. Considering how $\mathbf{3}$ would ionize leads to the conclusion that the product of matched ionization $(\mathbf{3} \rightarrow \mathbf{1 2})$ would retain the $R$ stereocenter and lead to the unobserved product $\mathbf{1 0}$ after intermolecular alkylation. While intermolecular alkylation of $\mathbf{1 2}$ appears reasonable, the competing intramolecular alkylation leading back to 3 by the pendant carboxylate is likely kinetically favored. Due to relative rates, this sets up a Curtin-Hammett type situation where the rapid and reversible matched ionization is unproductive. Mismatched ionization leads to 13, which undergoes $\pi-\sigma-\pi$ interconversion to relieve steric repulsion between the substrate and the wall of the ligand. This process gives $\mathbf{1 1}$ which is then alkylated in an intra- or intermolecular fashion to provide $(\boldsymbol{S}, \boldsymbol{S})$-2 or the observed product $(\boldsymbol{S}, \boldsymbol{S})-\mathbf{9}$.

Since a 1:2:1 ratio of $(\boldsymbol{S}, \boldsymbol{S})-\mathbf{2 : 3}:(\boldsymbol{R}, \boldsymbol{R})-\mathbf{2}$ is used in the reaction (Table 1, entry 7), the proposed mechanism explains how $\mathbf{2}$ and $\mathbf{3}$ can be converted into the same product and predicts a maximum yield of $75 \%$, but it also suggests that 3 could be converted to 2 under the reaction conditions. To probe this issue, the reaction was run with only enough 6 to form the active catalyst (Table 2). Under the standard conditions, only a trace amount of carbonate $\mathbf{3}$ remained and 2 was isolated in $14 \%$ yield (entry 1). The low recovery is likely due to decomposition of the $\pi$-allylpalladium complexes formed after decarboxylation. When the reaction is run under an atmosphere of $\mathrm{CO}_{2}$, the mass recovery improves significantly and provides $(\boldsymbol{S}, \boldsymbol{S})-\mathbf{2}$ in $75 \%$ ee (entry 2). Further evidence to support the proposed mechanism was obtained by running the reaction at lower temperature to determine if there is any effect on ee. Since we propose that both $(\boldsymbol{S}, \boldsymbol{S})-\mathbf{2}$ and $(\boldsymbol{S}, \boldsymbol{S})-\mathbf{9}$ are formed from $\mathbf{3}$ by a mismatched ionization $(\mathbf{3} \rightarrow \mathbf{1 3}$, Scheme 2$)$, a reverse temperature effect should be observed because at lower temperature the selectivity should shift towards the product of the matched reaction. This is indeed the case. When the 
reaction is conducted at $-25^{\circ} \mathrm{C}$ (entry 3 ), the ee of recovered $(\boldsymbol{S}, \boldsymbol{S})$-2 is significantly lower indicating that the matched ionization leads instead to $(\boldsymbol{R}, \boldsymbol{R})-\mathbf{2}$.

In order to probe the robustness of this system and for synthetic purposes, the use of oxygen nucleophiles to produce monoprotected 1,2-diols was studied (Table 3). Employing $p$ methoxyphenol 15, the desired branched product 16 was formed along with the linear product 17. While the combined yields and ratios required improvement (entries 1,2), 16 was obtained in $99 \%$ ee. Several modifications were made to the reaction conditions in an attempt to improve this ratio. While use of only the $d l$-isomer 2 had very little impact (entry 3), slow addition of the nucleophile at $0{ }^{\circ} \mathrm{C}$ both with and without $\mathrm{Na}_{2} \mathrm{CO}_{3}$ improved the ratio to 2.3:1 (entries 4, 5). Although only a modest improvement, these experiments seemed to indicate that decreasing the rate of nucleophilic attack would improve the yield of the branched product. Instead of further changes in the reaction conditions, the phenol was modified to slow the reaction. Use of the more sterically hindered phenol $\mathbf{1 8}$ with racemic ligand improved the ratio from 1.5:1 to $7.5: 1$ (entries 1,6) and also gave $\mathbf{1 9}^{11}$ in higher yield. When the catalyst loading, equivalents of $\mathbf{1 8}$, and temperature were lowered, $\mathbf{1 9}$ was isolated in $64 \%$ yield (theoretical max. $75 \%$ ) with $98 \%$ ee in a 12:1 ratio with $\mathbf{2 0}$ (entry 7).

Under the optimized conditions (Table 3, entry 7), $(\boldsymbol{R}, \boldsymbol{R})-\mathbf{2}$ could be reisolated from the reaction mixture and although differences are observed, the same mechanism (Scheme 2 ) is proposed to be operative. Appearance of the linear products $\mathbf{1 7}$ and $\mathbf{2 0}$ is likely due to matched nucleophilic addition to $\pi$-allylpalladium complex 13. Additional evidence of this is obtained by assignment of the absolute stereochemistry. While racemic material failed to separate on a variety of chiral stationary phase HPLC columns, both the configuration and ee could be determined by NMR. ${ }^{12}$ After conversion to the $O$-methyl mandalate ester, the major product was determined to be of the $S$ configuration and the ee was $60 \%$. These data are also consistent with the proposed mechanism. The principle difference between the phenol and phthalimide reactions is the solubility of the nucleophile. Phthalimide is only partially soluble, while the phenols completely dissolve under the reaction conditions. With phthalimide proper balance is achieved, but the higher concentration of phenol present increases the rate of nucleophilic addition relative to equilibration of the $\pi$-complexes and leads to a less regioselective reaction.

The impetus for developing this chemistry was for application to the synthesis of natural products containing 1,2-amino alcohols or 1,2-diols, two relatively simple structures being the proposed structures of iso-cladospolide B 21a,b. ${ }^{13}$ The stereochemistry ofiso-cladospolide B (21a) was originally postulated to be analogous to the macrolide cladospolide $B,{ }^{13 c}, d$ but recent reports indicate a discrepancy as $\mathbf{2 1 b}$ was proposed based on NMR studies of material isolated from a marine fungus culture of a different source and by analogy to the pandangolides 1 and $1 \mathrm{a}$, of known stereochemistry that were also isolated. ${ }^{13 \mathrm{e}}$

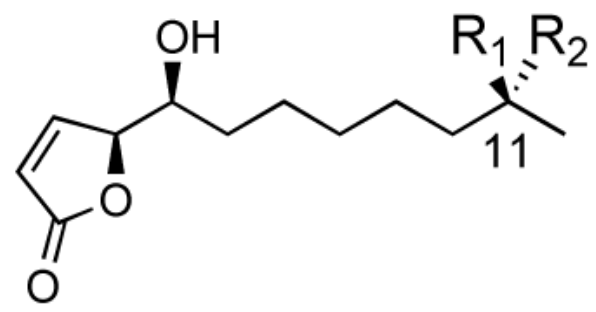

\section{Proposed Structures of iso-Cladospolide $\mathrm{B}$ $\begin{array}{ll}\text { 21a } & \mathrm{R}_{1}=\mathrm{H}, \mathrm{R}_{2}=\mathrm{OH} \\ \text { 21b } & \mathrm{R}_{1}=\mathrm{OH}, \mathrm{R}_{2}=\mathrm{H}\end{array}$}

Our strategy relies on a union of two fragments of defined stereochemistry to establish both the absolute and relative configuration. To this end, the alcohol 19 was acylated with acryloyl chloride and ring-closing metathesis (RCM) provided 22 (Scheme 3). Deprotection and crossmetathesis (CM) with the olefin $\mathbf{2 4}^{14}$ assembled the carbon framework in good yield. 
Chemoselective reduction of the allylic olefin proved more difficult than anticipated and required that the butenolide olefin be protected. Conjugate addition of thiophenol and oxidation of the resultant sulfide to the sulfone followed by hydrogenation and elimination provided 21a in $52 \%$ yield over 4 steps. The optical rotation, $[\alpha]_{\mathrm{D}}{ }^{23}-87.5$ (c $0.25, \mathrm{MeOH}$ aq.) $\left\{\right.$ lit. ${ }^{13 \mathrm{a}}$ $\left.[\alpha]_{\mathrm{D}}-90(\mathrm{c} 0.23, \mathrm{MeOH})\right\}$, and spectral data for synthetic $21 \mathrm{a}$ matched the data reported for the natural material. ${ }^{13 \mathrm{a}, \mathrm{c}, \mathrm{d}}$ Additionally, 21b was prepared by an analogous route from $\mathbf{2 3}$ and ent-24, and the spectroscopic data was indistinguishable from 21a within experimental error. The optical rotation, $[\alpha]_{\mathrm{D}}{ }^{23}-60.4$ (c 0.23 , distilled $\left.\mathrm{MeOH}\right)$ matched the literature value for recently isolated material $\left\{\right.$ lit. $\left.^{13 \mathrm{e}}[\alpha]_{\mathrm{D}}-61(\mathrm{c} 16.6, \mathrm{MeOH})\right\}$. Both diastereomers appear to be natural products that are structurally related to known macrolides and $\mathbf{2 1 b}$ should be referred to as 11-epi-iso-cladospolide B.

In summary, an efficient preparation of synthetically useful intermediates in high ee from a mixture of the cyclic carbonates $d l$ - and meso-1,2-divinylethylene carbonate has been developed whereby two different modes of asymmetric induction give the same product in excellent ee. This process, combined with ring closing and cross metathesis, provides rapid access to a wide range of useful synthons from the feedstock chemical acrolein. Further studies to understand the mechanism and the broad utility of the products will be the subjects of future reports.

\section{Supplementary Material}

Refer to Web version on PubMed Central for supplementary material.

\section{Acknowledgement}

We thank the National Science Foundation and National Institutes of Health for their generous support of our programs. A.A. is supported by an NIH postdoctoral fellowship. Mass spectra were provided by the Mass Spectrometry Regional Center of the University of California-San Francisco, supported by the NIH Division of Research Resources.

\section{References}

(1). Trost BM. J. Org. Chem 2004;69:5813. [PubMed: 15373468]

(2). Trost BM. Chem. Pharm. Bull 2002;50:1. [PubMed: 11824567]

(3). Trost BM, Bunt RC, Lemoine RC, Calkins TL. J. Am. Chem. Soc 2000;122:5968.

(4)(a). Burke SD, Sametz GM. Org. Lett 1999;1:71. [PubMed: 10822536] (b) Quinn KJ, Isaacs IK, Andres JM. Org. Lett 2004;6:4143. [PubMed: 15524428] (c) Quinn KJ, Isaacs IK, DeChristopher BA, Szklarz SC, Arvary RA. Org. Lett 2005;7:1243. [PubMed: 15787477] (d) Michaelis S, Blechert S. Org. Lett 2005;7:5513. [PubMed: 16288544]

(5). Braun RA. J. Org. Chem 1963;28:1383.

(6). Hekmatshoar R, Yavari I, Beheshtiha YS, Heravi MM. Montash. Chem 2001;132:689.

(7)(a). Trost BM, Weber L. J. Am. Chem. Soc 1975;97:1611. (b) Trost BM, Verhoeven TR. J. Am. Chem. Soc 1976;98:630. [PubMed: 1245689] (c) Hayashi T, Hagihara T, Konishi M, Kumada M. J. Am. Chem. Soc 1983;105:7767. (d) Fiaud JC, Legros LY. J. Org. Chem 1987;52:1907. (e) Stary I, Zajicek J, Kocovsky P. Tetrahedron 1992;48:7229.

(8). The relative configuration of 9 was determined by conversion to the corresponding $N$-tosyloxazolidinone and comparison to the known cis- and trans- $N$-tosyl-oxazolidinones:Kimura $\mathrm{M}$, Tanaka S, Tamaru Y. Bull. Chem. Soc. Jpn 1995;68:1689.The absolute configuration was determined to be $S, S$ by conversion to the known saturated amino alcohol:Andres JM, de Elena N, Pedrosa R, Perez-Encabo A. Tetrahedron 1999;55:14137.

(9). To the best of our knowledge, only one Pd AAA of an acyclic meso bis-electrophile has been reported and it was in an intramolecular cyclization:Jiang L, Burke SD. Org. Lett 2002;4:3411. [PubMed: 12323031]

(10). Trost BM, Toste FD. J. Am. Chem. Soc 1999;121:4545. 
(11). The stereochemistry of 19 was determined by conversion to the diol which has previously been prepared from monosaccharides:(a) Criegee R, Hoger E, Huber G, Kruck P, Marktscheffel F, Schellenberger H. Justus Liebigs Ann. Chem 1956;599:81-125. (b) Crombez-Robert C, Benazza M, Frechou C, Demailly G. Carbohydr. Res 1997;303:359.

(12). Trost BM, Belletire JL, Godleski S, McDougal PG, Balkovec JM. J. Org. Chem 1986;51:2370.

(13)(a). Smith CJ, Abbanat D, Bernan VS, Maiese WM, Greenstein M, Jompa J, Tahir A, Ireland CM. J. Nat. Prod 2000;63:142. [PubMed: 10650098] (b) Jadulco R, Proksch P, Wray V, Sundarsono, Berg A, Grafe U. J. Nat. Prod 2001;64:527. [PubMed: 11325242] (c) Franck X, Araujo MEV, Jullian JC, Hocquemiller R, Figadere B. Tetrahedron Lett 2001;42:2801. (d) Pandey SK, Kumar P. Tetrahedron Lett 2005;46:6625. (e) Gesner S, Cohen N, Ilan M, Yarden O, Carmeli S. J. Nat. Prod 2005;68:1350. [PubMed: 16180812]

(14). Dixon DJ, Ley SV, Tate EW. J. Chem. Soc., Perkin Trans. 1 2000:2385. 


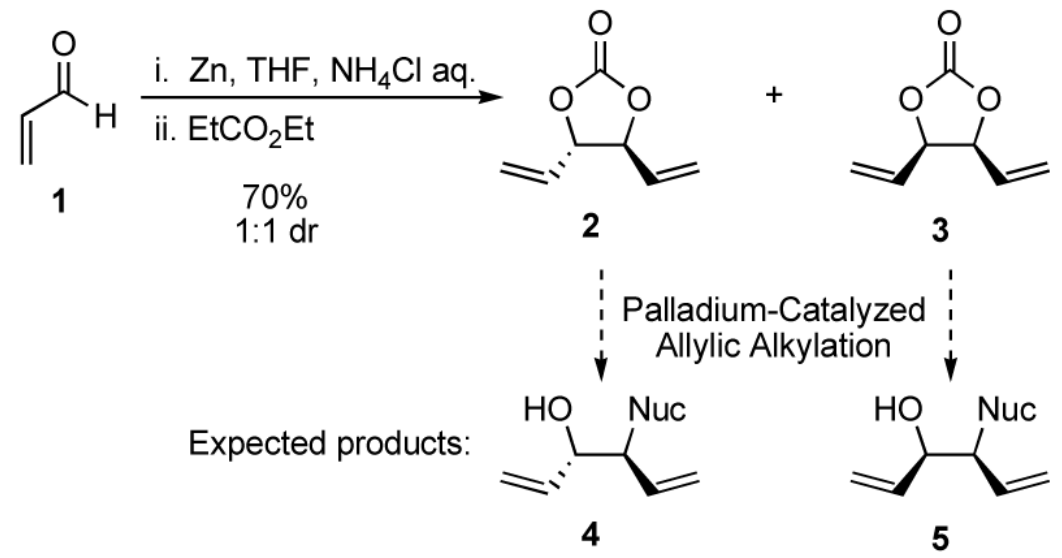

Scheme 1.

Pd AAA of Meso- and $d l$-1,2-Divinylethylene Carbonate. 


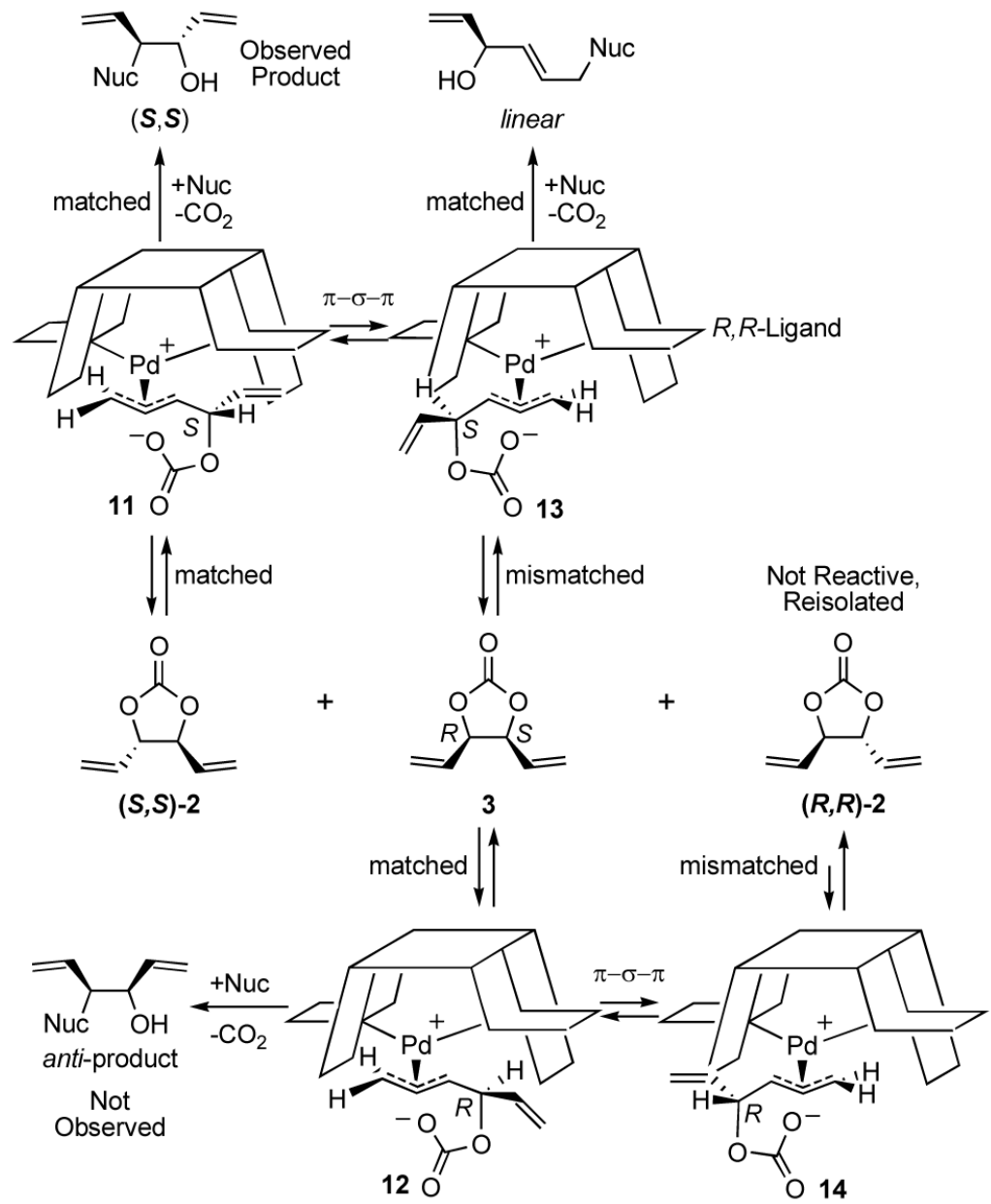

Scheme 2.

Mechanism of Pd-Catalyzed AAA of meso- and $d l$ - divinylethylene carbonate. 

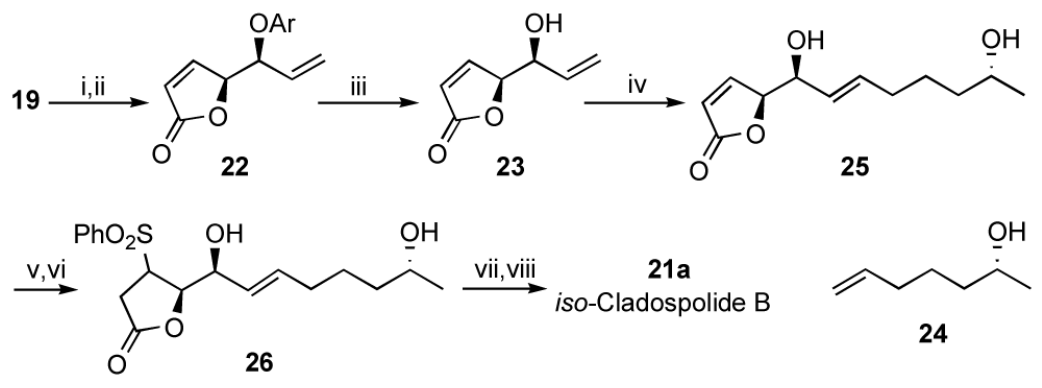

Scheme 3.

Synthesis of iso-Cladospolide B.

i. Acryloyl chloride, DMAP, $\mathrm{Et}_{3} \mathrm{~N}, \mathrm{CH}_{2} \mathrm{Cl}_{2}, 71 \%$; ii. $10 \mathrm{~mol} \%$ Grubbs $2^{\text {nd }}$ generation catalyst (27), $\mathrm{CH}_{2} \mathrm{Cl}_{2}, 70 \%$; iii. $\mathrm{CAN}, \mathrm{CH}_{3} \mathrm{CN} / \mathrm{H}_{2} \mathrm{O}, 70 \%$; iv. 24 (5 eq.), 27 (10 mol\%), $\mathrm{CH}_{2} \mathrm{Cl}_{2}, 73 \%$; v. $\mathrm{PhSH}, \mathrm{Et}_{3} \mathrm{~N}$ (5 mol\%), $\mathrm{CH}_{2} \mathrm{Cl}_{2}, 77 \%$; vi. oxone, $\mathrm{MeOH} / \mathrm{H}_{2} \mathrm{O}, 82 \%$; vii. $\mathrm{H}_{2}, 10 \% \mathrm{Pd} / \mathrm{C}$; viii. $\mathrm{DBU}, \mathrm{CH}_{2} \mathrm{Cl}_{2}$., $82 \%$ (2 steps). 


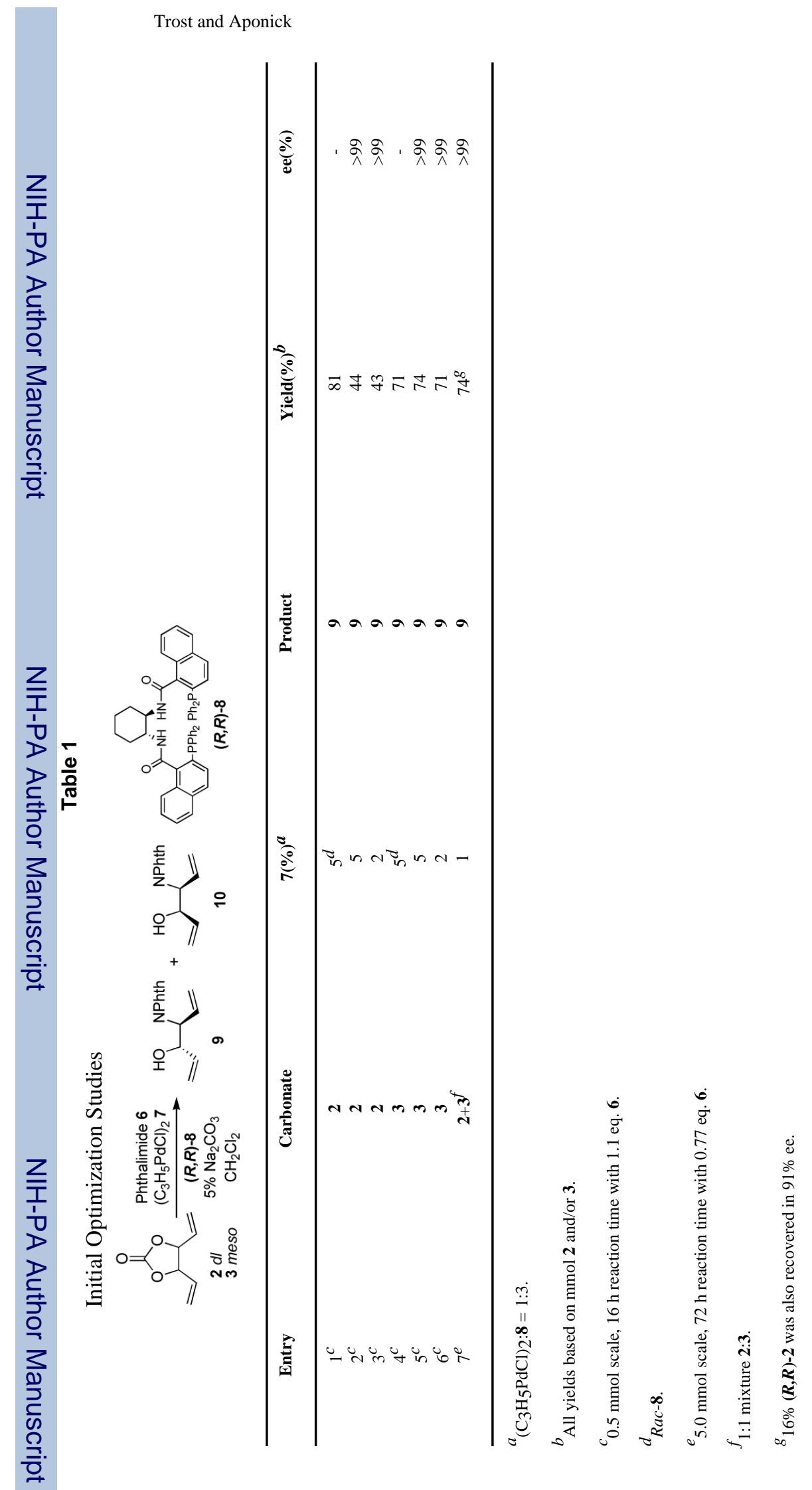


Table 2

Interconversion of $\mathbf{2}$ and $\mathbf{3}$

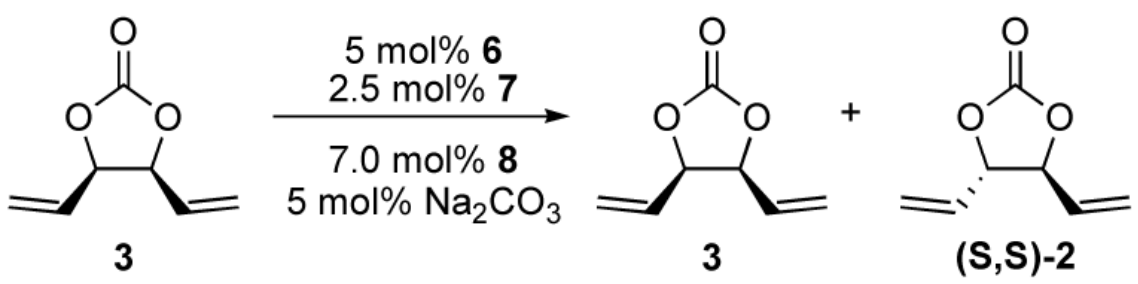

\begin{tabular}{ccccc}
\hline Entry & Temp $\left({ }^{\circ} \mathbf{C}\right)$ & Yield 3 $(\%)$ & Yield 2 (\%) & ee $(\boldsymbol{S}, \boldsymbol{S})$-2 (\%) \\
\hline $1^{a}$ & 25 & trace & 14 & nd \\
$2^{b}$ & 25 & 21 & 21 & 75 \\
$3^{b}$ & -25 & 64 & 12 & 53 \\
\hline
\end{tabular}

${ }^{a} \mathrm{~N}_{2}, 1 \mathrm{~atm}$.

${ }^{b} \mathrm{CO}_{2}, 1 \mathrm{~atm}$ 


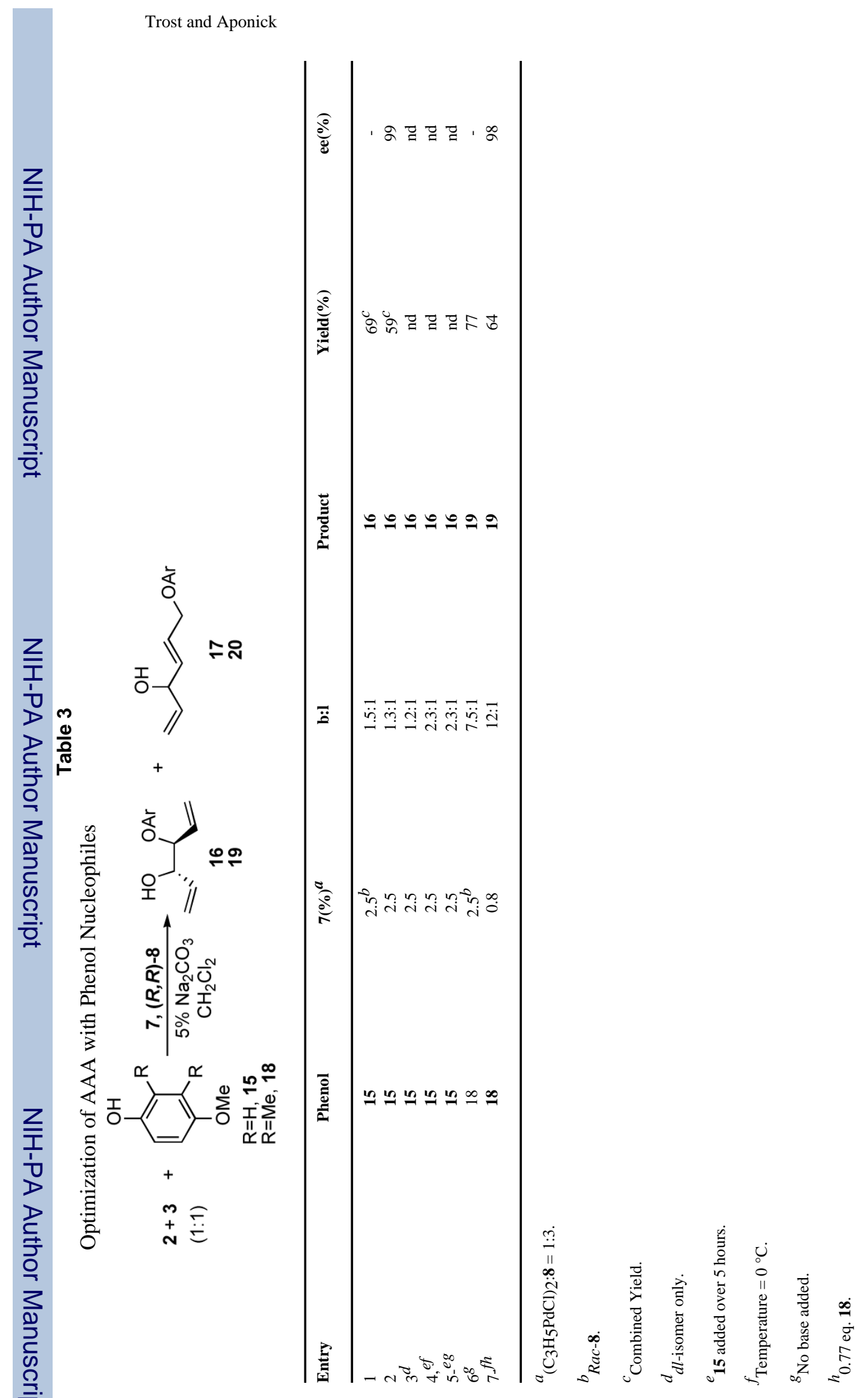

